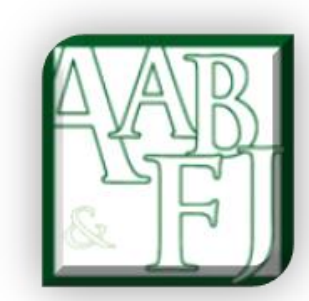

\title{
Does Financial Literacy Moderate the Relationship among Demographic Characteristics and Financial Risk Tolerance? Evidence from Egypt
}

\author{
Amir Ali Shusha ${ }^{1}$
}

\begin{abstract}
Financial risk tolerance is certainly an important topic for researchers, investors and personal financial planners or consultants. The study purposed to investigate the effect of demographic characteristics on financial risk tolerance among Egyptians. A literature review of demographic determinants of financial risk tolerance showed dialectical results. Therefore, this study attempts to clarify the debatable of these results by studying the moderating role of financial literacy in relationships among demographic characteristics and financial risk tolerance. The study sample included 386 respondents representing different segments of Egyptian people. Using the hierarchical regression analysis, the results demonstrated that there were significant effects of gender, age, educational level and annual income on financial risk tolerance. Moreover, the financial literacy moderates the relationships among demographic characteristics of individuals and their tendency to take a risk.
\end{abstract}

JEL Classification: N25, D14, D31, G02

Keywords: financial risk tolerance, financial literacy, demographic characteristics, moderated role, personal finance, Egypt.

${ }^{1}$ Damietta University, Egypt 


\section{Introduction}

Over the past few decades, the study of how individuals make their financial decisions has become important to researchers, personal financial planners, investment counselors and policy makers especially considering the new changes that have increased the economic landscape complex. In this context, Grable (2016) stated that examination and understanding the role of financial risk tolerance in forming of the financial behaviors has gained more attention. Moreover, he generally described risk tolerance as a situation where an individual wants to engage in a behavior to achieve a certain objective, but achieving of this objective is uncertain and fraught with the possibility of loss.

Within the domain of financial decision-making, an individual's tendency to take a risk performs crucial role in the making of financial decisions and in achieving financial goals. Yao, Gutter and Hanna (2005) stated that risk attitude is an important determinant of individual's investment behavior, so estimating the individual tendency to take a financial risk is a vital matter. Therefore, many researchers from different disciplines have analyzed how risk, risk perception and risk tolerance influence individuals when they take financial choices under uncertainty. Weber, Blais and Betz (2002) defined "risk attitude" as the individual's willingness to take a risk, which ranges from risk averse to risk seeking.

According to Per Grable (2008) financial risk tolerance is the maximum amount of uncertainty someone is willing to accept when making a financial decision. Whilst, Boone and Lubitz (2003) suggested that financial risk tolerance is a combination of both risk attitude and risk capacity, where risk attitude means how much risk someone choose to take and risk capacity means how much risk someone can afford to take. In this context, Lucarelli and Brighetti (2011) clarified that these two components of risk tolerance are substantially different where risk attitude is a psychological attribute while risk capacity is a financial attribute.

Sitkin and Pablo (1992) suggested that risk tolerance characterized by risk preference, risk perception and risk propensity. They distinguished among the three features of risk tolerance by defining risk preference as a personality trait of being attracted to risk, whereas risk perception as an individual's assessment of a situation-specific risk, and risk propensity as the objective likelihood of an individual taking or avoiding risk.

Van-de-Venter, Michayluk and Davey (2012) distinguished risk into subjective and objective financial risk tolerance. They defined subjective financial risk as the risk that an individual prefers to accept, while objective financial risk is a risk that an individual can take. In this context, Hallahan, Faff and McKenzie (2004) investigated the relationship between subjective and objective estimates of risk tolerance, and explored the relationship between risk tolerance and investor's demographical characteristic. Their results showed that investor's self-assessed risk tolerance accords with the risk tolerance scores. Add to that, their results demonstrated that gender, age, number of dependents, marital status, income, and wealth significantly related to risk tolerance scores.

Snelbecker, Roszkowski and Cutler (1991) asserted the importance of risk tolerance as a determinant of a wide range of personal financial decisions. Moreover, Grable (2016) pointed to 
risk tolerance as an underlying factor within financial planning models and investment suitability analyses. Campbell, (2006) also clarified that risk tolerance can influence individual behavior in situations such as savings, borrowing, type of mortgage and management of credit cards. Add to that, risk tolerance affects the way people invest their financial resources to achieve their goals, such as saving for a significant purchase or retirement. Therefore, there is an expectation that people with varying levels of risk tolerance should act differently when making investment decisions (Grable, 2016).

Grable (1997) investigated the demographical determinants of investor risk tolerance and differentiated among levels of investor risk tolerance to classify individuals into risk tolerance categories. The studied demographical variables were gender, age, marital status, occupation, selfemployment, income, race, and educational level. He relied on the financial management model of Leimberg and his colleagues of 1993 to explain how individual investors allocate investments to meet their financial objectives. Moreover, he applied a multiple discriminant analysis using data sample of 2,626 individual investors from Survey of Consumer Finances. His results showed that factors: gender, married, single but previously married, professional occupational status, selfemployment status, income, White, Black, and Hispanic racial background, and educational level were differentiated among levels of individual investors to risk tolerance. However, factors such as age, Asian racial background, and never married did not perform any role in differentiating among individual investors to risk tolerance. Finally, he reported that there is a need for more research to determine additional factors that can explain the differences in financial risk tolerance.

\section{Literature Review}

This section reviews literature about the determinants of financial risk tolerance and consequences of financial literacy.

\section{Demographic determinants of financial risk tolerance}

Bajtelsmit and Bernasek (1996) asked the following question: Why do females invest in a different way than males? They showed that females' attitudes toward risk tolerance are lower than males. Several previous studies showed that males are more risk tolerance than females and therefore males preferred more risky assets (Palsson, 1996; Hartog, Ferrer-i-Carbonell, and Jonker, 2000; Al-Ajmi, 2008; Faff, Mulino and Chai, 2008; Frijns, Koellen and Lehnert, 2008; and Gilliam, Chatterjee and Zhu, 2010). Powell and Ansic (1997) concluded that males had a much higher risk tolerance than females regardless the level of their knowledge. Coleman (2003) proved that males exhibited a higher level of risk tolerance when compared to women. Nonetheless, when comparing the ratio of risky assets to net worth for the same age categories, there was no significant difference in this ratio for men and women younger than forty years but women over forty years had a lower than men in the same age category. Add to that, Schubert, Brown, Gysler and Brachinger, (1999) showed that the differences in the financial risk tolerance of males and females depending on the financial decision frame. Moreover, Strydom and Metherell (2012) revised findings of previous studies that males were more risk loving than females and concluded that the differences in risk attitudes between males and females may due to that opportunity sets rather than stereotypic risk attitudes. 
Using a sample where males and females had the same education, Strydom, Christison and Gokul, (2009) presented evidence that males favored higher levels of financial risk tolerance. Furthermore, Yao and Hanna (2005) studied the effect of gender on financial risk tolerance among 24,037 households over 18 years from 1983 to 2001 . They confirmed that attitude to financial risk tolerance is high for males than females. Moreover, they showed that single males and females are more risky than married males and females. Barber and Odean (2001) justified that males being more likely to take risks than females because of their overconfidence where males are more confident than females. Moreover, Chen and Volpe (2002) suggested that differences in financial risk tolerance between males and females could affected by their understanding of financial knowledge. In another interpretation, Bernasek and Shwiff (2001) supposed that females are more exposure to poverty when they are older because weakness of their income over the lifetime. Therefore, females are unable to accumulate valuable savings or invest precious amount of money. Add to that, the life expectancy indicates that ages of females are longer than males which means that their savings need to spread out over a longer period. Otherwise, Gumede (2009) showed that differences in financial risk tolerance between males and females were not significant.

The life-cycle risk aversion hypothesis supposed that risk aversion increases with age where risk aversion is another pole of risk tolerance. In other words, there is an expectation that financial risk tolerance decreases as individuals get older as younger. Using data of 26,759 residents in USA, Gilliam, Chatterjee and Zhu (2010) examined the differences in financial risk tolerance among older people and younger people. They found that younger people were more risk tolerant than older people. Al-Ajmi (2008) explained the life-cycle hypothesis that younger individuals have more time to recover any financial losses and can replace leisure time with more work to compensate any losses. Moreover, several studies such as Faff and McKenzie, (2003); Hallahan, Faff and McKenzie (2004); Jianakoplos and Bernasek, (2006) and Faff, Hallahan and McKenzie (2009) presented evidence that risk tolerance decreased with age.

In contrast, Frijns, Koellen and Lehnert (2008) distributed a web questionnaire among university students and employees interested in financial topics. They demonstrated that age as demographic driver of financial risk tolerance affected portfolio choices. In more detail, the older people invested a greater proportion of their wealth in risky assets. The proportion of risky assets is an objective measure to financial risk tolerance (Bakshi and Chen, 1994). Per Yao and Hanna (2005) indicated that risky assets are "the sum of stocks, bonds, mutual funds, real estate other than owneroccupied home, equity in own business, and loans." Moreover, Wang and Hanna (1997) tried to answer the following question: Does risk tolerance decrease with age? They measured the risk tolerance by the ratio of risky assets to total wealth. Their results demonstrated that the proportion of net wealth invested in risky assets increases as people age. Therefore, they refused life-cycle risk aversion hypothesis and suggested that the pattern of relationship between age and risk tolerance is reverse of common pattern. Grable and Lytton (1999) also presented evidence that older individuals revealed higher levels of risk tolerance than younger. They concluded that age accounts for a relatively small amount of the variation in financial risk tolerance.

Several studies showed that there were a positive association between the levels of education and financial risk tolerance (Donkers, Melenberg and Van-Soest 2001; Chang, DeVaney and Chiremba, 2004; Kimball, Sahm and Shapiro, 2008; and Gilliam, Chatterjee and Zhu, 2010). Bellante and Green (2004) confirmed that the differences in education accounted for larger variations in asset 
allocation than any other determinants they investigated. In comparing subjective and objective risk tolerance, Chang, DeVaney and Chiremba (2004) presented evidence that education was a significant predictor of each subjective risk tolerance and the ratio of risky assets to net worth as an indicator to objective risk tolerance. Otherwise, Hallahan, Faff and McKenzie (2003) found that education could not explain the variations in individual's risk attitude.

There is a common expectation that individuals with high income or wealth are more likely to tolerate risk than others because of their ability to stand losses are greater (Cohn, Lewellen, Lease and Schlarbaum, 1975). Nevertheless, Strydom and Metherell (2012) said that the converse of this thesis might also be true because individuals may become wiser with higher income to avoid losing their hard-earned wealth. In this context, Morin and Suarez (1983) confirmed that the trend of families in the upper wealth group to tolerate risk is increasing. Add to that, they found that wealth is the most important determinant of risk tolerance. Grable and Lytton (1999) showed that a higher level of income has a positive effect on willingness to tolerate a risk. Similarly, Hartog, Ferrer-iCarbonell, and Jonker (2000); Faff, Hallahan and McKenzie (2009) and Gilliam, Chatterjee and Zhu (2010) confirmed that risk aversion fell as income or wealth increased. Hallahan, Faff and McKenzie (2004) also presented evidence that wealth and risk tolerance displayed a positive association. In other words, there was a positive relationship between financial risk tolerance and each of income and wealth. Moreover, Schooley and Worden (1996) found that the level of wealth induces individuals to hold risky assets.

Barber and Odean (2001) deduced that single persons held more risky assets than those who were married. Hallahan, Faff and McKenzie (2004) showed that single person was more risk tolerant than married person. Therefore, the marital status performed as a significant predictor of financial risk tolerance. Hawley and Fujii (1993) demonstrated that married men and male heads of households had very similar risk preferences, whereas single men favored a higher level of financial risk. They showed that married women were the most risk tolerant, followed by single women and then female heads of households. Moreover, Yao, Gutter and Hanna (2005) declared that married females preferred lower levels of financial risk when compared to married men, whereas single males were more willing to take a financial risk than married males. Otherwise, Hallahan, Faff and McKenzie (2003) found that marital status could not explain the variations in individual's risk attitude.

\section{Financial literacy and its consequences}

Servon and Kaestner (2008) stated that financial literacy is a person's ability to understand and utilize of financial concepts. U.S. Financial Literacy and Education Commission (2007) defined financial literacy as "the ability to use knowledge and skills to manage financial resources effectively for a lifetime of financial well-being." Furthermore, Remund (2010) defined financial literacy as a measure of the degree to which one understands key financial concepts and possesses the ability and confidence to manage his or her personal finances. After a review of previous studies, Huston (2010) defined financial literacy as a process of understanding and applying financial concepts and developing techniques to manage financial resources effectively.

Yao, Sharpe and Wang (2011) proposed a new research track where they noted that there was a gap for studies on the use of financial literacy as a predictor of financial risk tolerance. Moreover, Ryack (2011) claimed that studying the role of financial education and financial literacy in relation 
to financial risk tolerance is one approach that has not been receiving enough attention. Although, a few of earlier studies such as Grable (2000) and Hallahan, Faff and McKenzie (2004) introduced an evidence that financial literacy and having a high level of education were both correlated with increased financial risk tolerance. Recently, Gustafsson and Omark (2015) asked the following question: Do individuals differ in financial risk tolerance due to their level of financial literacy? They distributed the questionnaire of Grable and Lytton (1999) to measure financial risk tolerance among a sample of Swedish responders with an economic and noneconomic background. Regardless of the academic background of the responder, their results showed that financial literacy has made a positive effect on financial risk tolerance.

Chen and Volpe (1998) investigated the impact of financial literacy on financial opinions and decisions among 924 of American students. Their results showed that lower levels of financial literacy led to adopt wrong financial opinions and decisions. In the same context, Shusha (2016) investigated the role of financial literacy as a predictor of financial well-being among Egyptians. Using data sample of 386 respondents, his results displayed that financial literacy was cognitive determinant of financial well-being. In South Africa, Kojo Oseifuah (2010) evaluated financial literacy among youth and its impact on entrepreneurship skills. He showed that financial literacy among youth had significantly contributes to their entrepreneurship skills.

Bucher-Koenen and Lusardi (2011) pointed out to lacking financial literacy among German women, especially who live in East Germany, with low education and low income. They also found a positive impact of financial knowledge on retirement planning. Interestingly, there was no gender disparity in financial knowledge in the East Germany. Moreover, Landerretche and Martínez (2013) showed that Chileans people with greater knowledge about their pension system were more likely to have additional financial savings. Add to that, they indicated that improving in the pension literacy survey had positive influence on the personal tendency to save. Moreover, they introduced evidence that pension literacy had a significantly effect on worker choices regarding their pension savings. Their results also showed that employees that are more literate were more likely to involve in pension fund type switching.

In the Arab environment, Ibrahim and Alqaydi (2013) studied financial literacy among a sample of residents in the United Arab Emirates and its relationship with personal debt. Their results pointed to the average level of financial literacy in UAE were lower than the average level reported in the literature. In addition, they reported that tendency of individuals to borrow was less likely with high level of financial literacy. In addition, Shahrabani (2012) investigated the financial literacy among other determinants of intent to control a personal budget among college students. $\mathrm{He}$ indicated that intentions of students to govern their personal budget affected by level of financial literacy. Moreover, financial literacy had positive impact on intents to control the personal budget.

The current study seeks to investigate the effects of demographic characteristics on financial risk tolerance. Additionally, after reviewing the literature of financial literacy, it seems that research gap which declared by Yao, Sharpe and Wang (2011) and Ryack (2011) still lingers. Therefore, one of purposes of this study will investigate the direct effect of financial literacy on financial risk tolerance. Moreover, this study will test the moderate role of financial literacy in the relationships among demographic characteristics and financial risk tolerance. The conflicting results of previous 
studies were the main drive for studying the moderating role of financial literacy in the relationship between demographic characteristics and financial risk tolerance. Baron and Kenny (1986) showed that using a variable for potential moderation primarily introduced when there were inconsistent results between the independent and dependent variables. Moreover, according to Baron and Kenny (1986) a moderator variable can be a qualitative or quantitative (e.g., level of financial literacy) variable that affects the direction and/or strength of the relation between an independent variable (e.g., gender, age, educational level, number of dependents, annual income) and dependent variable (e.g., Financial risk tolerance). Therefore, this study seeks to test the following model.

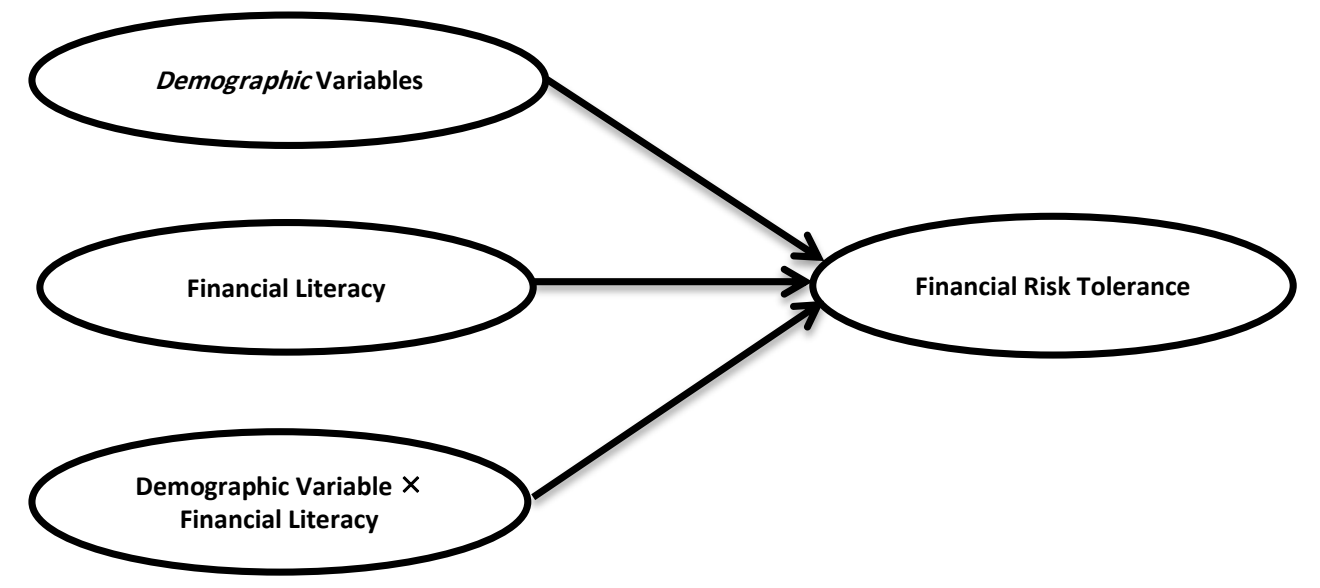

Figure (1): The Study Model

Based on the review of risk tolerance literature and the study model, this study will test the following hypotheses:

H1: There is a relationship between demographic variables and financial risk tolerance.

H2: There is a relationship between financial literacy and financial risk tolerance.

H3: Financial literacy moderates the relationship between demographic variables and financial risk tolerance.

\section{Methodology:}

This section discusses the method of selecting the sample and sample specifications, the tools and procedures for collecting the data, and tests the validity and reliability of variables measures. Add to that, the appropriate statistical procedures for testing the study hypotheses will be determined.

\section{The study sample}

This study depends on a questionnaire to collect the required data from the expected population. The population of this study is Egyptian adults. Due to the absence of a complete and accurate sampling frame, this study depends on convenience sample. A team of assistant researchers distributed 500 questionnaires on Egyptian individuals within June of 2015. The response rate is about $81 \%$ where 405 questionnaires backed. However, the effective response rate is about $77 \%$ because of the missing data of some questionnaires. Table 1 describes the sample characteristics; 
$57 \%$ approximately of the sample was comprised of males and $43 \%$ of females. In terms of age, nearly $43 \%$ of the respondents were less than 35 years, $39 \%$ ranging from 35 to less than 50 years, and $18 \%$ more than 50 years. Regarding the educational level, approximately $25 \%$ of the respondents had high school, 57\% had university degree, and 21\% had high diploma, or Master's or $\mathrm{PhD}$. About annual income, around $45 \%$ of the respondents their annual income was less than 50,000 Egyptian Pound (EGP), 39\% their annual income ranging from 50,000 EGP to 150,000 EGP and $16 \%$ their annual income was more than 150,000 EGP. Regarding the number of dependents, $35 \%$ approximately of respondents were singles, $37 \%$ of respondents were breadwinner for one and up to three individuals, and $28 \%$ of respondents were breadwinner for more than three individuals

Table 1

Sample characteristics

\begin{tabular}{lcc}
\hline \multicolumn{1}{c}{ Variables } & Frequently & Percent \% \\
\hline Gender & 221 & 57.3 \\
Male & 165 & 42.7 \\
Female & & \\
Age & 165 & 42.7 \\
Less than 35 years & 152 & 39.4 \\
From 35 to 50 years & 69 & 17.9 \\
More than 50 years & & \\
Educational level & 98 & 25.3 \\
High school & 207 & 53.6 \\
University degree & 81 & 21.1 \\
High diploma or Master's or PhD degree & & \\
Annual income & 175 & 45.3 \\
Less than EGP 50,000 & 150 & 38.9 \\
From EGP 50,000 to EGP 150,000 & 61 & 15.8 \\
More than EGP 150,000 & & \\
Number of dependents & 134 & 34.7 \\
No one & 143 & 37.0 \\
From 1 to 3 & 109 & 28.3 \\
More than 3 & 386 & 100 \\
\hline Number of observations &
\end{tabular}

\section{Measures and its validity and reliability}

Regarding demographic variables, gender measured on binary scale where one means male and two means female. Age of respondent measured on tri-scale where one means less than thirty-five years, two means ranging from 35 to less than 50 years, and three means more than 50 years. Educational level of respondent measured on tri-scale where one means high school, two means university degree, and three means high diploma or master's or PhD. Annually income of respondent measured on tri-scale, where one means less than EGP 50,000, two means income was ranging from EGP 50,000 to EGP 150,000, and three means income was more than EGP 150,000. Moreover, number of respondents was measured on 3-point scale, where 1 means the respondent 
was single, 2 means the respondent was breadwinner for one and up to three individuals, 3 means the respondent was breadwinner more than 3 individuals.

\section{Financial literacy scale}

Chen and Volpe (1998) designed a comprehensive questionnaire to measure the financial literacy. This questionnaire was a cornerstone to develop the 16-items of financial literacy instrument by Shusha (2016). Moreover, the validity of the scale measured by principal components extraction of factor analysis. Table 2 illustrates the results of principal components extraction which show that item loadings ranging from 0.43 to 0.85 , therefore each item of the scale add value per standardized value which is 0.4 (Hinkin, 1995). Add to that, the results of Cronbach's alpha test of the instrument show that the reliability coefficient is 0.82 , which means that the scale of financial literacy is reliable per standardized value which determined by Nunnally and Bernstein (1994). Add to that, financial literacy measured on a binary scale where 1 means answer of the responder was correct and 0 means answer of the responder was wrong.

\section{Table 2}

Results of principal components extraction of financial literacy instrument items

\begin{tabular}{lc}
\hline Statements & Factor \\
loading
\end{tabular}

Personal financial planning involves preparing plans for future financial needs and goals.

Personal financial literacy leads healthy spending habits.

Money invested in a certificate of deposit more liquid than checking account.

The personal net worth is the difference between expenditures and income.

Saving accounts in a commercial bank insured by central bank.

Deposit EGP 1,000 at 5\% for a year mean that balance in a year will be higher if the interest rate compounded monthly rather than quarterly.

The interest rate on credit card is higher than the rate of return on a certificate of deposit.

Personal credit report received from a commercial bank.

The main purpose to purchase insurance provides protection from loss occurred recently.

Type and age of vehicle is one of premium determinants.

Risks such as war, flood, and earthquake cover by a homeowner policy.

A term insurance policy is lower expensive than life insurance.

High-risk high return investment strategy is more suitable for a young couple than an elderly retired one.

If interest rate rises, the price of a bond will increase.

Investing in a single stock is safer than a mutual fund.

A mutual fund is a diversified collection of securities used as an investment vehicle. 


\section{Financial risk tolerance scale}

There is no consensus on how to measure the financial risk tolerance (Roszkowski \& Grable, 2005). The study of Roszkowski \& Grable (2005) aimed to answer the following question: how should risk tolerance measured? After their review of a risk tolerance measures, they noted that there are four techniques to assess individual attitudes toward a risk tolerance:
a. Asking about investment choices,
b. Asking a combination of investment measures and subjective questions,
c. Assessing actual behavior,
d. Asking hypothetical questions with carefully specified scenarios.

The most common of these methods in risk tolerance literature are assessing actual behavior and asking hypothetical questions with carefully specified scenarios. Bakshi and Chen (1994) assumed that risk aversion could measure by the proportion of risky assets hold by individual. The study measured risk tolerance by asking questions about hypothetical scenarios. This is an appropriate method to assess Egyptians' risk tolerance because of culture, where most of Egyptians tend to refrain to disclosure their financial decisions and positions. Moreover, some respondents may do not have actual investments or still in thinking stage to invest their money. Therefore, they still select the level of financial risk tolerance that they would be most likely to take if they had money to invest. Grable and Lytton (1999) developed a risk tolerance instrument depending on analyzing theoretical, procedural, and empirical issues related to the development of a financial risk tolerance instrument. They developed an instrument consist of 13-items to assess financial risk tolerance. Their results showed that the instrument is valid and reliable. Based on financial risk tolerance of Grable and Lytton (1999), this study developed a financial risk tolerance to appropriate Egyptian or Arabian culture. The validity of the scale measured by principal components extraction of factor analysis. The results of principal components extraction shown in Table 3 illustrate that item loadings range from 0.45 to 0.74 that means each item of the 10 -items add value to the scale. Add to that, the results of Cronbach's alpha test of the instrument of financial risk tolerance show that the reliability coefficient was 0.73 . Add to that, responses to financial risk tolerance were measured on ranging scale from 1 to 4 or sometimes 3 , where 1 means that respondent tend to be risk averse and 4 or 3 means that respondent tend to be risk seeker.

Table 3

Results of principal components extraction of items of financial risk tolerance instrument

Factor
Loading

1. When you think about the term of risk, which of the following meaning comes to your mind first?
a) Loss
b) Uncertainty
c) Opportunity
d) Excitement

2. In general, how do you describe yourself as a risk taker?

a) A real risk avoider

b) Careful

c) Willing to take the risk after careful consideration

d) A real risker 
Table 3 (Continued)

Results of principal components extraction items of financial risk tolerance instrument items

3. If you are on a television game show, which of the following would you choose.

a) EGP 1,000 in cash

b) A $50 \%$ probability to win EGP 5,000

c) A $25 \%$ probability to win EGP 10,000

d) A $5 \%$ probability to win EGP 100,000

4. If you plan to invest EGP 100,000, which of the following alternatives would you find most attractive.

a) Allocation $50 \%$ or more in low-risk investments

b) Allocation $50 \%$ or more in medium-risk investments

c) Allocation $50 \%$ or more in high-risk investments

5. From your perspective, how do you see investing in stocks?

a) Disturbing

b) Somewhat comfortable

c) Very relaxing

6. If you decide to invest EGP 100,000, what would you do?

a) Deposit it in a bank account

b) Invest it in high quality bonds

c) Invest it in stocks

d) Invest it in option and future contracts

7. Investments can go up and down in value. Given the best and worst case of expected returns of the four investment choices below, which would you prefer.

a) Gain EGP 1000 or nothing

b) Gain EGP 2,000 or loss EGP 200

c) Gain EGP 5,000 or loss EGP 1,500

d) Gain EGP 10,000 or loss EGP 5,000

8. If you have, EGP 100,000 and you should invest all the money in one of the following investment choices, which of them is most appealing for you.

a) A money market mutual fund

b) A mutual fund that owns stocks and bonds

c) A portfolio of 10 common stocks

d) Commodities, e.g. gold, silver, and oil

9. Your trusted friend is an experienced geologist. He is founding fund to explore gold mining venture. The venture could pay back 50 to 100 times the investment if successful. Your friend estimates the probability of success is only $25 \%$. If you had the money, how much would you invest?

a) Nothing

b) EGP 10,000

c) EGP 30,000

d) EGP 50,000

10. If the expectations of experts point to rising real estate prices, most of your investment assets are now in government bonds. Which of the following changes you have made in your investments?

a) Hold the bonds

b) Sell half of the bonds and invest the money earned in real estate

c) Sell the bonds and invest all the money earned into real estate

d) Sell the bonds and invest all the money earned into real estate, and borrow additional money to buy more

The total score of financial risk tolerance is thirty-eight; the two cutoff points used to divide the study sample per their attitudes toward the risk. Where score is less than sixteen that means the 
respondent has a high tendency to avoid risk, while score is ranging between sixteen and twentyfive that means the respondent has a moderate tendency to take the risk, and if the score is more than twenty-five that means the respondent has a high tendency to take the risk.

The study adopted on Pearson correlation to test the relationships of the study variables. Additionally, the multiple regression analysis applied to test the effects of demographic variables on financial risk tolerance, the effect of financial literacy on financial risk tolerance, and testing the moderation role of financial literacy among demographic characteristic and financial risk tolerance. The three regression models presented in the following:

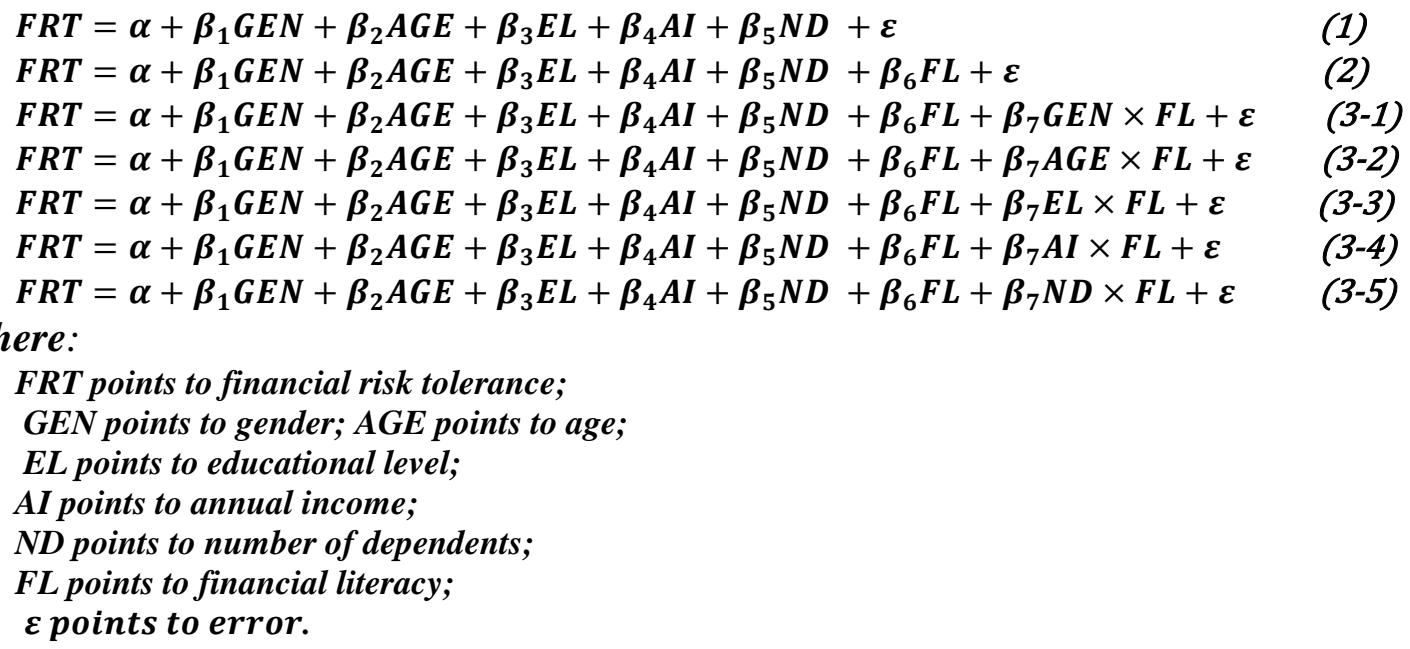

FRT points to financial risk tolerance;

GEN points to gender; $A G E$ points to age;

EL points to educational level;

AI points to annual income;

ND points to number of dependents;

FL points to financial literacy;

$\varepsilon$ points to error.

Where:

Note that in the following tables, which display the results of statistical analysis these symbols will use rather than variable names.

\section{Results}

To test the relationships among the study variables, this study uses the non-directional of Pearson's correlation test because the study hypotheses do not have any expected sign. The critical value of Pearson's correlation coefficient is 0.1129 at level of significance equal 0.05 and the degree of freedom is 384 where the sample size is 386 respondents.

Table 4

Summary of Pearson's correlation among study variables

\begin{tabular}{lccccccc}
\hline \multicolumn{1}{c}{ Variables } & $\boldsymbol{G E N}$ & $\boldsymbol{A G E}$ & $\boldsymbol{E L}$ & $\boldsymbol{A I}$ & $\boldsymbol{N D}$ & $\boldsymbol{F L}$ & $\boldsymbol{F R T}$ \\
\hline $\boldsymbol{G} \boldsymbol{E} \boldsymbol{N}$ & 1 & & & & & & \\
$\boldsymbol{A} \boldsymbol{G} \boldsymbol{E}$ & 0.709 & 1 & & & & & \\
$\boldsymbol{A I}$ & 0.911 & 0.940 & 1 & & & & \\
$\boldsymbol{N} \boldsymbol{D}$ & 0.153 & 0.232 & 0.195 & 1 & & & \\
$\boldsymbol{F L}$ & -0.133 & 0.103 & -0.179 & -0.107 & 1 & 1 & \\
$\boldsymbol{F R} \boldsymbol{T}$ & 0.809 & 0.153 & 0.347 & 0.404 & -0.309 & 0.413 & 1 \\
\hline
\end{tabular}

Table 4 presents the coefficients of Pearson's correlation among study variables. The results of Pearson's correlation test highlight that there are: 
- Positive significant relationship between educational level and financial literacy.

- Positive significant relationship between annual income and financial literacy.

- Negative significant relationship between number of dependents and financial literacy.

- Negative significant relationship between gender and financial risk tolerance.

- Negative significant relationship between age and financial risk tolerance.

- Positive significant relationship between educational level and financial risk tolerance.

- Positive significant relationship between annual income and financial risk tolerance.

- Negative significant relationship between number of dependents and financial risk tolerance.

- Positive significant relationship between financial literacy and financial risk tolerance.

Table 5

Summary of Hierarchical Regression Analysis for Variables Predicting financial risk tolerance

\begin{tabular}{|c|c|c|c|c|c|c|c|}
\hline \multirow{3}{*}{$\begin{array}{c}\text { Regression } \\
\text { Models / } \\
\text { Variables }\end{array}$} & \multirow{2}{*}{$\begin{array}{l}\text { Model } \\
\text { (1) }\end{array}$} & \multirow{2}{*}{$\begin{array}{l}\text { Model } \\
\text { (2) }\end{array}$} & \multicolumn{5}{|c|}{ Model (3) } \\
\hline & & & $(3-1)$ & $(3-2)$ & $(3-3)$ & $(3-4)$ & $(3-5)$ \\
\hline & $\beta^{\text {(Sig.) }}$ & $\boldsymbol{\beta}^{(\text {Sig. })}$ & $\beta^{(\text {Sig. })}$ & $\beta^{\text {(Sig.) }}$ & $\beta^{\text {(Sig.) }}$ & $\beta^{(\text {Sig. })}$ & $\beta^{(\text {(Sig.) }}$ \\
\hline Constant & $0.372^{* * *}$ & $0.212^{* *}$ & $0.232^{* * *}$ & $0.182^{* *}$ & $0.271^{* * *}$ & $0.198^{* * *}$ & $0.163^{* *}$ \\
\hline GEN & $0.191^{* *}$ & $0.174^{* *}$ & $0.111^{*}$ & $0.104^{*}$ & $0.122^{* *}$ & $0.181^{* *}$ & $0.172^{* *}$ \\
\hline$A G E$ & $-0.113^{*}$ & $-0.201^{* *}$ & $-0.103^{*}$ & $0.151^{* *}$ & $-0.110^{*}$ & $-0.112^{*}$ & $-0.111^{*}$ \\
\hline$E L$ & $0.112^{*}$ & $0.108^{*}$ & 0.082 & 0.098 & 0.079 & 0.074 & 0.082 \\
\hline$A I$ & $0.138^{* *}$ & $0.188^{* *}$ & $0.176^{* *}$ & $0.188^{* *}$ & $0.149^{* *}$ & $0.179^{* *}$ & $0.129^{* *}$ \\
\hline$N D$ & $-0.135^{* *}$ & $-0.136^{*}$ & $-0.104^{*}$ & $-0.136^{*}$ & $-0.121^{*}$ & $-0.105^{*}$ & $-0.103^{*}$ \\
\hline$F L$ & & $0.191^{* *}$ & $0.212^{* *}$ & $0.121^{* *}$ & $0.133^{* *}$ & $0.156^{* * *}$ & $0.142^{* *}$ \\
\hline$G E N \times F L$ & & & $0.134^{* *}$ & & & & \\
\hline$A G E \times F L$ & & & & $0.212^{* *}$ & & & \\
\hline$E L \times F L$ & & & & & $0.153^{* *}$ & & \\
\hline$A I \times F L$ & & & & & & $0.163^{* *}$ & \\
\hline$N D \times F L$ & & & & & & & $0.172^{* *}$ \\
\hline $\begin{array}{l}F^{(s i g)} \\
R^{2}\end{array}$ & $53.709^{* *}$ & $89,191^{* *}$ & $96.326^{* *}$ & $103.114^{* * *}$ & $113.153^{* * *}$ & $106.134^{* *}$ & $109.153^{* * *}$ \\
\hline$R^{2}$ & 0.211 & 0.293 & 0.318 & 0.323 & 0.362 & 0.353 & 0.362 \\
\hline
\end{tabular}

Note that $* p<.05 . * *<<.01$.

Table 5 presents a summary of the hierarchical regression. Demographic variables e.g. gender, age, educational level, annual income and number of dependents entered at the first regression model. Financial literacy added at the second regression model. Moreover, the interaction between financial literacy and each demographic variable added at the third regression model. The results showed that all regression models were significance.

The results of the first regression model showed that all demographic variables were predictors of financial risk tolerance at the different levels of significance. These results showed that:

- There was positive impact of each gender and annual income on financial risk tolerance $(\mathrm{p}<.01)$.

- There was negative impact of number of dependents on financial risk tolerance $(\mathrm{p}<.01)$.

- There was negative impact of age on financial risk tolerance $(\mathrm{p}<.05)$.

- There was positive impact of educational level on financial risk tolerance $(\mathrm{p}<.05)$. 
After inserting financial literacy in the second regression model, the results showed that all demographic variables as well as financial literacy were predictors of financial risk tolerance at the different levels of significance, but some changes happened as follows:

- There was positive impact of financial literacy on financial risk tolerance $(p<.01)$.

- The negative impact of age on financial risk tolerance became stronger where the level of significance changed to become $\mathrm{p}<.01$.

- The negative impact of number of dependents on financial risk tolerance became weaker where the level of significance changed to become $\mathrm{p}<.05$.

The third regression model showed that the interaction effect of financial literacy and each demographic variable on financial risk tolerance. The results of this model demonstrated the following:

- The results of model (3-1) showed that the $\beta$ coefficient of gender decreased and the level of significance changed to become $\mathrm{p}<.05$.

- The results of model (3-2) showed that the sign of $\beta$ coefficient of age changed from negative to positive. Add to that, the level of significance changed to become $p<.01$.

- The results of model (3-3) showed that the $\beta$ coefficient of educational level become nonsignificance.

- The results of model (3-4) showed that the $\beta$ coefficient of annual income decreased but still negative at the same level of significance $\mathrm{p}<.01$.

- The results of model (3-5) showed that the $\beta$ coefficient of number of dependents decreased and the level of significance changed to become $\mathrm{p}<.05$.

These results confirmed that financial literacy performs a moderate role in the relationship among individual demographic characteristics and their tendency to take a risk.

\section{Discussion}

Numerous studies supported that the tendency of males to take a risk is more likely than females (Riley and Chow, 1992; Grable, 2000; Barber and Odean, 2001; Hallahan, Faff and McKenzie, 2003; Frijns, Koellen and Lehnert, 2008 and Thanki, 2015). These studies showed that males are overconfident and undertake riskier behaviours than females. In this area, the results of this study agree with the results of previous studies showed that males are riskier than females. Add to that, the result of interactive impact of gender and financial literacy on financial risk tolerance showed that the beta coefficient is decreased which means that differences between males and females retracted when each of them has high levels of financial literacy.

The relationship between age and risk tolerance is a controversial issue. There is a widespread belief among academicians and financial planners that the tendency to take the risk decreases with age. This belief has been supported by some studies, such as Morin and Suarez (1983); Riley and Chow (1992); and Hallahan, Faff and McKenzie (2004). Other studies such as Palsson (1996); Wang and Hanna (1997); Grable (2000); and Frijns, Koellen and Lehnert (2008) demonstrated that tendency to take the risk increases with age. In this context, Wang and Hanna (1997) justified that young people are more risk averse because of low ability to withstand losses in the short term 
considering their limited financial resources. From another viewpoint, Chang, DeVaney and Chiremba (2004) investigated determinants of subjective and objective risk tolerance. They showed that younger and older people tend to be less risk tolerant than people with aged from 35 to 49 and 50 to 64 . Therefore, they believed that the relationship between age and subjective risk tolerance was hump-shaped. The results of this study showed that this conflict is ostensible where financial literacy amended the relationship between age and risk tolerance from negative to positive relationship. This result means that the negative relationship between age and the tendency to take the risk prevails among people with low levels of financial literacy, while this relationship converts to positive among people with high levels of financial literacy.

Using data sample of 20,415 respondents, Hallahan, Faff and McKenzie (2003) found that the level of education could not explain the differences of risk tolerance among people. In 2004, they came back to prove that the level of education had positive impact on financial risk tolerance. Their results correspond with other studies such as Riley and Chow (1992); Grable (2000) and Chang, DeVaney and Chiremba (2004). The results of this study can explain that dilemma where the strong relationship between the level of education and financial risk tolerance converts positive significant to non-significant by inserting the interactive of educational level and financial literacy in regression model. This result means that education patterns that support financial background of people more likely reflected in shape of high level of willingness to take a risk.

Chang, DeVaney and Chiremba (2004) showed that the relationship between income and subjective risk tolerance is positive and significant. Moreover, many studies have shown that higher income motivate people to be risk seekers (Morin and Suarez, 1983; Riley and Chow, 1992; Grable, 2000 and Hallahan, Faff and McKenzie, 2004). With respect to that, the results of this study supported the finding of previous studies. Moreover, the result of interactive impact of income and financial literacy on financial risk tolerance showed that the beta coefficient is increased which means that the effect of income became stronger when people have high level of financial literacy.

In contrastive with common literature of financial risk tolerance, the researchers decided to study the number of dependents rather than marital status for many reasons. First, the number of dependents is discrete variable but marital status is nominal variable which the opportunity to measure more accurately. Second, in Arab environment the number of dependents may not related to marital status because of the phenomenon of social solidarity. In this context, Hallahan, Faff and McKenzie (2004) confirmed that number of dependents has negative and significant impact related to financial risk tolerance. The results of this study confirmed the negative impact of number of dependents on financial risk tolerance. Moreover, the severity of negative impact of number of dependents on financial risk tolerance became less powerful by inserting the interactive term of number of dependents and financial literacy in regression model. This result means that the impact of number of dependents on financial risk tolerance depends on the level of financial literacy.

There are some limitations restrict the results of this study. Firstly, the study sample selected by non-probability sampling. Second, the study is a cross-sectional where the study variables measured at the certain point of time. Thirdly, the study depended on a subjective method to measure of financial risk tolerance. These limitations may limit the study conclusions and may 
limit generalization of the study results. Nevertheless, the results are consistent with literature of financial risk tolerance and its antecedents.

\section{Conclusion}

Financial risk tolerance is certainly an important topic for researchers, investors and personal financial planners or consultants. This study investigated the direct effect of demographic characteristics of Egyptians on their tendency to take a risk. Moreover, the study engaged the moderate role of financial literacy in the relations among individual demographic characteristics and financial risk tolerance. Well-known measures of the financial literacy and financial risk tolerance were adapted to fit Arabian culture. Add to that, the validity and reliability of these measures tested by principal components extraction of factor analysis and Cronbach's alpha. The study sample consists of 386 respondents representing different segments of Egyptian people. The main statistical methods used to test the study hypotheses were Pearson's correlation test and hierarchical regression analysis. The results confirmed that there were effects of demographic characteristics on financial risk tolerance. Moreover, the results demonstrated that financial literacy moderates the relationships among demographic characteristics of individuals and their tendency to take a risk. Therefore, the importance of this study stems from trying to interpret the controversial results for effecting of demographic characteristics on the financial risk tolerance.

\section{References}

Al-Ajmi, J. Y. (2008). Risk tolerance of individual investors in an emerging market. International Research Journal of Finance and Economics, 17(1), 15-26.

Bajtelsmit, V. L., \& Bernasek, A. (1996). Why do women invest differently than men?. Financial Counseling and Planning.

Bakshi, G. S., \& Chen, Z. (1994). Baby boom, population aging, and capital markets. Journal of Business, 165-202. https://doi.org/10.1086/296629

Barber, B. M., \& Odean, T. (2001). Boys will be boys: Gender, overconfidence, and common stock investment. Quarterly journal of Economics, 261-292. https://doi.org/10.1162/003355301556400

Baron, R. M., \& Kenny, D. A. (1986). The moderator-mediator variable distinction in social psychological research: Conceptual, strategic, and statistical considerations. Journal of personality and social psychology, 51(6), 1173. https://doi.org/10.1037/00223514.51.6.1173

Bellante, D., \& Green, C. A. (2004). Relative risk aversion among the elderly. Review of Financial Economics, 13(3), 269-281. https://doi.org/10.1016/j.rfe.2003.09.010

Bernasek, A., \& Shwiff, S. (2001). Gender, risk and retirement. Journal of Economic Issues, 35, 345-356. https://doi.org/10.1080/00213624.2001.11506368

Boone N. M., Lubitz L.S., (2003). A review of difficult investment policy issues, Journal of Financial Planning, May: 56-63.

Bucher-Koenen, T., \& Lusardi, A. (2011). Financial literacy and retirement planning in Germany. Journal of Pension Economics and Finance, 10(04), 565-584. https://doi.org/10.1017/S1474747211000485 
Campbell, J. Y. (2006). Household finance. The Journal of Finance, 61(4), 1553-1604. https://doi.org/10.1111/j.1540-6261.2006.00883.x

Chang, C. C., DeVaney, S. A., \& Chiremba, S. T. (2004). Determinants of subjective and objective risk tolerance. Journal of Personal Finance, 3(3), 53-67.

Chen, H., \& Volpe, R. P. (1998). An analysis of personal financial literacy among college students. Financial services review, 7(2), 107-128. https://doi.org/10.1016/S10570810(99)80006-7

Chen, H., \& Volpe, R. P. (2002). Gender differences in personal financial literacy among college students. Financial Services Review, 11(3), 289-307.

Cohn R. A., Lewellen, W. G., Lease, R. C. \& Schlarbaum, G. G. (1975). Individual investor risk aversion and investment portfolio composition. The Journal of Finance, 30 (2), 605-620. https://doi.org/10.1111/j.1540-6261.1975.tb01834.x

Coleman, S. (2003). Risk tolerance and the investment behavior of Black and Hispanic heads of household. Journal of Financial Counseling and Planning, 14(2).

Donkers, B., Melenberg, B., \& Van-Soest, A. (2001). Estimating risk attitudes using lotteries: A large sample approach. Journal of Risk and uncertainty, 22(2), 165-195. https://doi.org/10.1023/A:1011109625844

Faff, R., Hallahan, T., \& McKenzie, M. (2009). Nonlinear linkages between financial risk tolerance and demographic characteristics. Applied Economics Letters, 16(13), 1329-1332. https://doi.org/10.1080/13504850701381123

Faff, R., Mulino, D., \& Chai, D. (2008). On the linkage between financial risk tolerance and risk aversion. Journal of financial research, 31(1), 1-23. https://doi.org/10.1111/j.14756803.2008.00229.x

Frijns, B., Koellen, E., and Lehnert, T., (2008). On the determinants of portfolio choice. Journal of Economic Behavior and Organization, 66, 373-386. https://doi.org/10.1016/j.jebo.2006.04.004

Gilliam, J., Chatterjee, S., \& Zhu, D. (2010). Determinants of risk tolerance in the baby boomer cohort. Journal of Business \& Economics Research, 8(5). https://doi.org/10.19030/jber.v8i5.721

Grable, J. E. \& Joo, S. H. (2004). Environmental and biophysical factors associated with financial risk tolerance. Journal of Financial Counseling and Planning, 15(1).

Grable, J. E. \& Lytton, R. H. (1999). Financial risk tolerance revisited: the development of a risk assessment instrument. Financial services review, 8(3), 163-181. https://doi.org/10.1016/S1057-0810(99)00041-4

Grable, J. E. (1997). Investor risk tolerance: Testing the efficacy of demographics as differentiating and classifying factors (Doctoral dissertation, Virginia Polytechnic Institute and State University).

Grable, J. E. (2000). Financial risk tolerance and additional factors that affect risk taking in everyday money matters. Journal of Business and Psychology, 14(4), 625-630. https://doi.org/10.1023/A:1022994314982

Grable, J. E. (2008). Risk tolerance. In Handbook of consumer finance research (pp. 3-19). Springer New York. https://doi.org/10.1007/978-0-387-75734-6_1

Grable, J. E., (2016). Financial risk tolerance. In Handbook of Consumer Finance Research (pp. 19-31). J.J. Xiao (ed.). Springer, Switzerland. https://doi.org/10.1007/978-3-319-28887-1_2 
Gumede, V. (2009). Demographic determinants of financial risk tolerance: A South African perspective. Unpublished B. Com. Hon. Thesis. Pietermaritzburg: University of KwaZuluNatal.

Gustafsson, C., \& Omark, L. (2015). Financial literacy's effect on financial risk tolerance: A quantitative study on whether financial literacy has an increasing or decreasing impact on financial risk tolerance.

Hallahan, T. A., Faff, R. W., \& McKenzie, M. D. (2004). An empirical investigation of personal financial risk tolerance. Financial Services Review, 13(1), 57.

Hallahan, T., Faff, R., \& McKenzie, M. (2003). An exploratory investigation of the relation between risk tolerance scores and demographic characteristics. Journal of Multinational Financial Management, 13(4), 483-502. https://doi.org/10.1016/S1042-444X(03)00022-7

Hartog, J., Ferrer-i-Carbonell, A., \& Jonker, N. (2000). On a simple survey measure of individual risk aversion. https://doi.org/10.1080/01603477.1993.11489978

Hawley, C. B., \& Fujii, E. T. (1993). An empirical analysis of preferences for financial risk: Further evidence on the Friedman-Savage model. Journal of Post Keynesian Economics, 16(2), 197-204.

Hinkin, T. R. (1995). A review of scale development practices in the study of organizations. Journal of Management, 21(5), 967-988. https://doi.org/10.1177/014920639502100509

Huston, S. J. (2010). Measuring financial literacy. Journal of Consumer Affairs, 44(2), 296-316. https://doi.org/10.1111/j.1745-6606.2010.01170.x

Ibrahim, M. E., \& Alqaydi, F. R. (2013). Financial literacy, personal financial attitude, and forms of personal debt among residents of the UAE. International Journal of Economics and Finance, 5(7), 126-138. https://doi.org/10.5539/ijef.v5n7p126

Jianakoplos, N. A., \& Bernasek, A. (2006). Financial risk taking by age and birth cohort. Southern Economic Journal, 981-1001. https://doi.org/10.2307/20111864

Kimball, M. S., Sahm, C. R., \& Shapiro, M. D. (2008). Imputing risk tolerance from survey responses. Journal of the American statistical Association, 103(483), 1028-1038. https://doi.org/10.1198/016214508000000139

Kojo Oseifuah, E. (2010). Financial literacy and youth entrepreneurship in South Africa. African Journal of Economic and Management Studies, 1(2), 164-182. https://doi.org/10.1108/20400701011073473

Landerretche, O. M., \& Martínez, C. (2013). Voluntary savings, financial behavior, and pension finance literacy: evidence from Chile. Journal of Pension Economics and Finance, 12(03), 251-297. https://doi.org/10.1017/S1474747212000340

Lucarelli, C., \& Brighetti, G. (Eds.). (2011). Risk tolerance in financial decision making. Palgrave Macmillan. https://doi.org/10.1057/9780230303829

Morin, R. A. \& Suarez, A. F. (1983). Risk aversion revisited. The Journal of Finance, 38(4), 1201-1216. https://doi.org/10.1111/j.1540-6261.1983.tb02291.x

Nunnally, J. C., \& Bernstein, I. H. (1994). The assessment of reliability. Psychometric theory, 3(1), 248-292.

Palsson, A. M. (1996). Does the degree of risk aversion vary with household characteristics? Journal of Economic Psychology, 17, 771-787. https://doi.org/10.1016/S0167$\underline{4870(96) 00039-6}$ 
Powell, Melanie, and David Ansic, 1997, Gender Differences in Risk Behavior in Financial Decision-Making: An Experimental Analysis, Journal of Economic Psychology, 18(6): 605628. https://doi.org/10.1016/S0167-4870(97)00026-3

Remund, D. L. (2010). Financial literacy explicated: The case for a clearer definition in an increasingly complex economy. Journal of Consumer Affairs, 44(2), 276-295. https://doi.org/10.1111/j.1745-6606.2010.01169.x

Riley Jr, W. B., \& Chow, K. V. (1992). Asset allocation and individual risk aversion. Financial Analysts Journal, 48(6), 32-37. https://doi.org/10.2469/faj.v48.n6.32

Roszkowski, M. J., \& Grable, J. E. (2005). Estimating risk tolerance: The degree of accuracy and the paramorphic representations of the estimate. Journal of Financial Counseling and Planning, 16(2).

Ryack, K. (2011). The impact of family relationships and financial education on financial risk tolerance. Financial Services Review, 20(3), 181.

Schooley, D. K., \& Worden, D. D. (1996). Risk aversion measures: Comparing attitudes and asset allocation. Financial Services Review, 5, 87-99. https://doi.org/10.1016/S10570810(96)90003-7

Schubert, R., Brown, M., Gysler, M., \& Brachinger, H. W. (1999). Financial decision-making: are women really more risk-averse? The American economic review, 89(2), 381-385. https://doi.org/10.1257/aer.89.2.381

Servon, L. J., \& Kaestner, R. (2008). Consumer financial literacy and the impact of online banking on the financial behavior of lower-income bank customers. Journal of Consumer Affairs, 42(2), 271-305. https://doi.org/10.1111/j.1745-6606.2008.00108.x

Shahrabani, S. (2012). The effect of financial literacy and emotions on intent to control personal budget: A study among Israeli college students. International Journal of Economics and Finance, 4(9), p156. https://doi.org/10.5539/ijef.v4n9p156

Shusha, A. (2016). The Mediating Role of Rational Buying in the Relationship between Financial Literacy and Financial Well-being. Research Journal of Finance and Accounting, 7(3), 133-142.

Sitkin, S. B., \& Pablo, A. L. (1992). Reconceptualizing the determinants of risk behavior. Academy of management review, 17(1), 9-38.

Snelbecker, G. E., Roszkowski, M. J., \& Cutler, N. E. (1991). Investors' risk tolerance and return aspirations and financial advisors' interpretations: A conceptual model and exploratory data. Journal of Behavioral Economics, 19(4), 377-393. https://doi.org/10.1016/00905720(90)90024-2

Strydom, B. \& Metherell, C. (2012). Demographic factors affecting subjective financial risk tolerance: South African evidence. Working Paper No. 01-2012, School of Economics \& Finance.

Strydom, B., Christison, A., \& Gokul, A. (2009). Financial risk tolerance: A South African perspective. School of Economics \& Finance.

Thanki, H., (2015). Risk tolerance dependent on what? Demographics or personality type: findings from an empirical Research. Journal of Marketing and Consumer Research, 6, 4856.

U.S. Financial Literacy and Education Commission. (2007). Taking ownership of the future: The National Strategy for Financial Literacy. 
Van-de-Venter, G., Michayluk, D., \& Davey, G. (2012). A longitudinal study of financial risk tolerance. Journal of Economic Psychology, 33(4), 794-800. https://doi.org/10.1016/j.joep.2012.03.001

Wang, H., \& Hanna, S. D. (1997). Does risk tolerance decrease with age? Financial Counseling and Planning, 8(2).

Weber, E. U., Blais, A. R., \& Betz, N. E. (2002). A domain-specific risk-attitude scale: Measuring risk perceptions and risk behaviors. Journal of behavioral decision making, 15(4), 263-290. https://doi.org/10.1002/bdm.414

Yao, R., \& Hanna, S. D. (2005). The effect of gender and marital status on financial risk tolerance. Journal of Personal Finance, 4(1), 66.

Yao, R., Gutter, M. S., \& Hanna, S. D. (2005). The financial risk tolerance of Blacks, Hispanics and Whites. Journal of Financial Counseling and Planning, 16(1), 51-62.

Yao, R., Sharpe, D. L., \& Wang, F. (2011). Decomposing the age effect on risk tolerance. The Journal of Socio-Economics, 40(6), 879-887. https://doi.org/10.1016/j.socec.2011.08.023 